\title{
Políticas curriculares, Educação Básica brasileira, internacionalização: aproximações e convergências discursivas
}

\section{Resumo}

Juares da Silva Thiesen ${ }^{1}$

ORCID: 0000-0001-9299-4441

0 texto integra-se ao trabalho de pesquisa desenvolvido em estágio pós-doutoral que tem por objetivo geral analisar implicações dos movimentos de internacionalização curricular no/do Ensino Superior sobre as atuais políticas e reconfigurações curriculares na Educação Básica. No artigo em pauta, como recorte, exploro, com base nos textos oficiais da política curricular brasileira, quais demandas, em termos de metas, recomendações e orientações curriculares, aparecem associadas, de algum modo, com a internacionalização do currículo na Educação Básica. A identificação das referidas demandas é feita por meio de um mapeamento de textos oficiais que compõem a produção da política curricular instituída a partir dos anos 2000, usando-se um conjunto de descritores e categorias. No tratamento analítico dos dados, levo em conta que o sistema educacional brasileiro é permeável ao movimento global da internacionalização do currículo e que a formulação de suas políticas mais recentes reflete influências diretas deste contexto - o que Stephen Ball denomina contextos de influência. Os resultados mostram que há relativa identificação entre as atuais prescrições curriculares oficiais da Educação Básica brasileira e os requerimentos ou expectativas dos movimentos transnacionais de internacionalização, e que essa aproximação ocorre em diferentes aspectos da dinâmica curricular.

\section{Palavras-chave}

Internacionalização - Currículo - Educação básica - Política.

\section{Curriculum policies, Brazilian basic education and internationalization: discursive approximations and convergences}

\section{Abstract}

This article is part of a post-doctoral research project whose general objective is to analyze the implications of the movements of curriculum internationalization in and of higher

1- Universidade Federal de Santa Catarina, Florianópolis, SC, Brasil. Contato: juares.thiesen@ufsc.br

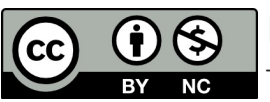


education over current policies and curriculum reconfigurations in basic education. The article analyzes official documents concerning Brazilian curriculum policy to explore what demands, in terms of curriculum goals, recommendations, and guidelines appear to be somehow associated with the internationalization of curriculum in basic education. The identification of the demands aforementioned uses a set of descriptors and categories in order to achieve a mapping of official documents that compose the production of the curriculum policy, established since the 2000's. In the analytical data treatment, I considered that the Brazilian educational system is permeable to the global movement of the internationalization of the curriculum and that the formulation of its most recent policies is reflected on direct influences of this context - which Stephen Ball calls contexts of influence. The results show that there is a relative identification between the current official curriculum prescriptions in Brazilian basic education and the requirements or expectations of the transnational movements for internationalization, and that this approximation takes place in different aspects of the curriculum dynamics.

\section{Keywords}

Internationalization - Curriculum - Basic education - Policy.

\section{Introdução}

0 presente texto integra-se ao trabalho de pesquisa que desenvolvo em estágio pós-doutoral e que tem por objetivo analisar implicações dos movimentos de internacionalização curricular no/do Ensino Superior sobre as atuais políticas e reconfigurações curriculares na Educação Básica, particularmente nos cenários do Brasil e de Portugal.

Como primeira tarefa científica no conjunto do trabalho, explorei, com base em pesquisas já realizadas, um conjunto de aspectos conceituais e outros elementos de contextualização do movimento de internacionalização da educação, com o propósito de destacar a presença da Educação Básica no debate da problemática que, como se sabe, tem a Educação Superior como locus principal. Resultados dessa etapa de pesquisa foram apresentados no texto intitulado Internacionalização dos currículos na educação básica: concepções e contextos (THIESEN, 2017).

No presente artigo socializo resultados da segunda etapa de pesquisa, que tem como objetivo identificar, especialmente nos documentos oficiais da política educacional e curricular brasileira, quais demandas, em termos de metas, recomendações e orientações curriculares, aparecem associadas, de algum modo, com a internacionalização do currículo na Educação Básica. No âmbito desta pesquisa, considero metas, recomendações e orientações curriculares qualquer indicação ou proposição impressa nos textos oficiais das instituições formuladoras da política curricular ou da legislação educacional orientada para seus respectivos sistemas de ensino.

A identificação das referidas demandas foi feita por meio de um mapeamento da produção da política educacional e curricular brasileira instituída oficialmente a partir dos anos 2000, cujos textos encontram-se disponibilizados em ambientes digitais das 
instituições e em repositórios diversos - trabalho este caracterizado como um estudo exploratório de base empírica. Para a identificação das marcações indicativas das demandas, considerei o seguinte quadro de fontes e descritores:

Quadro 1 - Fontes e descritores para identificação de demandas

\begin{tabular}{|c|c|c|}
\hline Fonte documental & Tipologia dos textos consultados & $\begin{array}{c}\text { Descritores } \\
\text { (palavras-chave para busca das marcações } \\
\text { nos textos) }\end{array}$ \\
\hline $\begin{array}{l}\text { - Documentos oficiais formulados em âmbito } \\
\text { nacional } \\
\text { - Documentos formulados por organizações } \\
\text { não estatais e/ou privadas }\end{array}$ & $\begin{array}{l}\text { - Leis educacionais do Sistema Nacional de } \\
\text { Educação } \\
\text { - Diretrizes Curriculares Nacionais } \\
\text { - Outros documentos de orientação } \\
\text { curricular em âmbito nacional }\end{array}$ & $\begin{array}{l}\text { - Internacionalização } \\
\text { - Internacional } \\
\text { - Internacionais } \\
\text { - Internacionalizado } \\
\text { - Mundialização } \\
\text { - Mundial } \\
\text { - Transnacional } \\
\text { - Transnacionalização } \\
\text { - Global }\end{array}$ \\
\hline
\end{tabular}

Fonte: Elaborado pelo autor (em 2017).

Para o tratamento analítico dos dados resultantes do mapeamento, levo em conta que o sistema educacional brasileiro é permeável ao movimento global da internacionalização do currículo e que a formulação de suas políticas mais recentes reflete as influências diretas desse contexto - o que Ball (1994) denomina contexto de influência.

Por essa razão, antes de apresentar o quadro com as demandas do sistema educacional brasileiro, elenco algumas indicações e recomendações com perspectivas de internacionalização propostas por organismos transnacionais - indicações que, em alguma medida, impactam sobre os currículos da Educação Básica brasileira. Analiso esse quadro em diálogo com outros pesquisadores citados no texto, os quais discutem a problemática, num esforço de evidenciar como esse movimento é compreendido, considerando-se diferentes nuances e pontos de vista. Para a breve contextualização, não estabeleço recorte espaço-temporal, tendo em vista tratar-se de um processo global e relativamente recente.

Amparando-me em Sevilha (2014), Aguiar (2007), Amorim (2012), Nogueira, Aguiar e Ramos (2008), Leask (2009, 2015), Knight (2004, 2008) e outros, compreendo internacionalização na Educação Básica como um movimento, ainda inicial, com motivações predominantemente políticas e econômicas, que se fortalece mobilizado por influências de organismos estatais ou privados que operam em espaços e instâncias transnacionais. Por diferentes estratégias e instrumentos, induzem estados nacionais e sistemas educacionais a desencadearem formulação e implantação de reformas em seus currículos de Educação Básica, alcançando, inclusive, espaços escolares. São processos que podem incluir desde a formulação de políticas curriculares mais amplas, até reconfigurações, redesenhos, adaptações ou adequações curriculares com foco nos conteúdos de conhecimento, nas aprendizagens dos estudantes, na avaliação e nas respectivas metodologias de ensino.

Em geral, configuram ações desenvolvidas com perspectivas de alinhamento da educação, do currículo e consequentemente da formação escolar aos padrões do sistema econômico mundial vigente, mas que são discursivamente apresentadas como alternativas 
de atualização, inovação, eficiência e modernização. Os primeiros passos desse movimento aparecem: em textos de políticas curriculares, que passam a inserir demandas e expectativas internacionais; nos processos de avaliação externa, que definem seus critérios com base em exigências internacionais; nos documentos de projetos e programas oficiais, em geral estruturados com base nesses mesmos princípios e propósitos; em alguns programas de formação inicial e continuada para professores etc.

\section{Indicações formuladas na perspectiva da internacionalização por organizações transnacionais que impactam os curriculos dos sistemas educacionais brasileiros}

Inicio a seção acentuando o que vários outros pesquisadores ${ }^{2}$ vêm afirmando quando tratam da relação entre políticas educativas e curriculares e as novas governanças no âmbito das redes políticas globais que se fortalecem neste início de século, alinhadas que estão às demandas da atual ordem econômica mundial. Trata-se, nos termos de Dale (2004, 2010), de uma agenda estruturada para a educação. Neste âmbito, estão colocadas questões gerais que dizem respeito aos vínculos da educação com os interesses do grande mercado, além de outras mais pontuais, a exemplo de demandas que incluem reformas e reconfigurações curriculares nos sistemas de ensino, novas competências docentes, maiores exigências e controle na avaliação dos resultados educacionais, novas competências esperadas para estudantes, maior eficiência e efıcácia nos sistemas, etc.

São demandas que se originam nos espaços onde se identificam interesses comuns do Estado e do mercado, institucionalizando-se por meio dos chamados organismos transnacionais ou multilaterais. Sabidamente, fazem parte dessa rede de governança transnacional (CÓSSIO, 2015) importantes organizações político-econômicas ou intergovernamentais, como é o caso do Banco Mundial ${ }^{3}$, do Programa das Nações Unidas para o Desenvolvimento (PNUD), da Organização para a Cooperação e Desenvolvimento Econômico (OCDE), do Banco Interamericano de Desenvolvimento (BID), além de várias outras, conforme identifica Silva (2010). ${ }^{4}$

\footnotetext{
2- A título de exemplo, cito: Ball (1994, 2014); Dale (2004, 2008); Ball e Mainardes (2011); Pacheco e Marques (2014); Libâneo (2014); Evangelista (2013, 2014); Freitas (2011, 2012); Evangelista e Shiroma (2006); Frigotto e Ciavatta (2003); e Leher (1998).

3- Segundo Cóssio (2015), os termos Banco ou Banco Mundial referem-se às duas instituições que formam o que é comumente chamado Banco Mundial: o Banco Internacional de Reconstrução e Desenvolvimento (BIRD), que faz empréstimos para países em desenvolvimento com renda per capita média, como o Brasil, ou para países de baixa renda solventes; e a Associação Internacional de Desenvolvimento (AID), que faz doações e empréstimos sem juros e com prazos maiores para os países mais pobres do mundo.

4- Para Silva (2010), os organismos internacionais podem ser divididos em instituições intergovernamentais: a) globais: Organização das Nações Unidas (ONU); Organização Mundial do Comércio (OMC); Organização Internacional do Trabalho (OIT); Organização Mundial da Saúde (OMS); Fundo Monetário Internacional (FMI); FAO; Banco Interamericano de Desenvolvimento (BID); Grupo Banco Mundial; Organização das Nações Unidas para a Educação, a Ciência e a Cultura (UNESCO); Fundo das Nações Unidas para a Infância (UNICEF); b) regionais: Organização dos Estados Americanos (OEA); Organização do Tratado do Atlântico Norte (OTAN); Organização para a Cooperação e Desenvolvimento Econômico (OCDE); Comissão Econômica para América Latina e Caribe (Cepal); Mercado Comum do Sul (Mercosul) e União Europeia. No geral, suas estruturas de funcionamento compreendem os principais órgãos: Assembleia Geral, Diretoria de Governadores e Secretariado Permanente. Para alcançar e monitorar os objetivos, contam, além da sede, com escritórios regionais ou agências em outros países. Há também aquelas não governamentais: Greenpeace, Cruz Vermelha, Aldeias Infantis e outras.
} 
Wielewicki e Oliveira (2010, p. 222) assinalam aspectos importantes desse contexto quando afirmam:

Em termos educacionais o período ao redor das décadas de 1980 e 1990 é marcado pela eclosão de um movimento de reformas educacionais por todo o mundo, instaurando aquilo que Hargreaves e outros (2002) denominam de "nova ortodoxia oficial”, um movimento que é caracterizado pela padronização em torno de políticas de avaliação, de financiamento, de formação de professores e de currículo, num processo de nítida sintonia entre tais políticas e a visão de desenvolvimento preconizada por grandes organismos financeiros internacionais como, por exemplo, o Banco Mundial.

São, portanto, movimentos que pressionam governos e seus respectivos sistemas educacionais para a formulação de reformas que, em geral, envolvem questões curriculares. Os argumentos que justificam iniciativas dessa natureza pautam-se, predominantemente, nos ideais de inovação, de melhoria da eficiência e da eficácia, com consequente elevação de resultados - todos alinhados aos padrões requeridos ou estabelecidos internacionalmente. Na educação superior, esse movimento é absolutamente evidente e inclusive constitui mote nas universidades e demais instituições de ensino superior brasileira para a (re)formulação dos chamados Projetos de Desenvolvimento Institucional (PDI) e Projetos Pedagógicos Institucionais (PPI).

Na Educação Básica, esses requerimentos são traduzidos fundamentalmente na proposição de diretrizes e demais prescrições curriculares, por intermédio de projetos de cooperação, pela implantação de mecanismos de avaliação externa no âmbito dos sistemas educativos e, ainda, pela regulação e pelo controle, por parte do Estado, via distribuição dos recursos financeiros - estratégias cada vez mais vinculadas à verificação de qualidade pelos indicadores de resultados.

Sem a pretensão de contemplar o vasto conjunto de indicações pautadas por esses organismos para a área da educação, especialmente as formuladas partir dos anos 1980, quando se fortalecem os movimentos de globalização da economia e, inclusive, das políticas educacionais (SUDBRACK; NEGRO, 2016), destaco a seguir, sumariamente, algumas cujos conteúdos mostram-se diretamente relacionados com questões curriculares.

Para Leher (1998), o documento Financiamento da educação nos países em desenvolvimento: uma exploração das opções políticas, de 1986, pode ser considerado um marco na intervenção do Banco Mundial no setor educacional. Todavia, foi nos anos 1990, com a publicação da trilogia Educação primária (em 1990), Educação profissional técnica e capacitação (em 1991) e Ensino superior: as lições da experiência (em 1994), que setores do Banco Mundial passaram a exercer papel decisivo na privatização de políticas sociais, impondo a lógica da substituição do público pelo privado, para além da imposição do capitalismo norte-sul.

0 texto de 1996 do Banco Mundial, intitulado Prioridades e estratégias para a educação, revela-se igualmente importante. No prólogo se encontram as razões e finalidades do documento, que tem a qualidade do ensino na Educação Básica como foco.

É o primeiro exame global do setor de educação publicado pelo Banco desde o documento de políticas sobre educação de 1980 - sintetiza as conclusões das publicações realizadas nos últimos 
anos. Acrescenta um exame da educação secundária que reflete os resultados dos trabalhos em andamento do Departamento de Desenvolvimento Humano do Banco e torna extensivos estes resultados às esferas do financiamento e da gestão setorial. Baseia-se também, consideravelmente, no informe mundial sobre a educação da UNESCO (1993). No informe se delineiam as opções de política que podem adotar os países de baixo e médio ingresso visando fazer frente aos problemas educacionais a medida que avançam para o século XXI. (BANCO MUNDIAL, 1996, p. 12, tradução nossa).

Algumas declarações de eventos internacionais mostram-se igualmente importantes, particularmente as declarações de Jomtien (UNICEF, 1990), de Nova Delhi (UNESCO, 1993) e de Dakar (UNESCO, 2000), além de documentos resultantes de eventos patrocinados por organismos como UNESCO, UNICEF, PNUD e BID, todos com expressiva repercussão na formulação de políticas curriculares dos sistemas educacionais, especialmente dos países signatários. São textos que, em geral, indicam a necessidade de melhoria nos resultados educacionais da Educação Básica por meio de reformas curriculares e apelam para a ampliação de financiamento e apoio internacional, especialmente dos países centrais.

Texto mais recente formulado pela equipe de estratégia para o setor de educação do Grupo Banco Mundial, intitulado Aprendizagem para todos: investir nos conhecimentos e competências das pessoas para promover o desenvolvimento - Estratégia de educação 2020 (2011), também repercute na Educação Básica. Trata-se de uma prescrição estratégica colocada como base de apoio aos estados nacionais e seus respectivos sistemas educacionais para que estes efetivem suas reformas curriculares de acordo com os princípios dessa agenda global. No sumário do projeto lê-se:

0 Grupo Banco Mundial está empenhado em consolidar esse progresso e a incrementar o seu apoio para ajudar todos os países a alcançarem a Educação para Todos (EFA) e os objetivos de educação das Metas de Desenvolvimento do Milênio (MDG). [...] A nova estratégia do Banco para 10 anos procura alcançar este objetivo alargado de "Aprendizagem para Todos", promovendo reformas nos sistemas de educação dos países e criando uma base global de conhecimento suficientemente forte para liderar estas reformas. (BANCO MUNDIAL, 2011, p. 1).

Alguns documentos do Conselho Europeu e do Conselho da União Europeia, que, entre outras indicações, recomendam a melhoria da eficácia dos processos educacionais de investigação e formação, além da abertura dos sistemas de educação ao mundo exterior, têm repercutido nos sistemas de ensino no Brasil. São vários os documentos ${ }^{5}$, alguns resultantes de conclusões de assembleia, relatórios de comissões por área ou ainda comunicações dessas comissões. Parte significativa dos textos reafirma a proposta de uma Europa com sistemas educacionais eficientes, abertos ao mundo da internacionalização. 0 processo de Bolonha, obviamente, integra esse contexto.

Documentos e programas da OCDE, com seu slogan "uma rede global de políticas" (OCDE, 2011), igualmente jogam forte influência nas formulações curriculares de países em desenvolvimento, como é o caso do Brasil. Dentre tantos, destaque-se o PISA (Programa

5- São vários os documentos publicados pelos Conselhos Europeu e da União Europeia sobre educação. 0 endereço para acessá-Ios é: <http:// www.consilium.europa.eu/pt/documents-publications/public-register/>. 
Internacional para o Acompanhamento das Aquisições dos Alunos) e os vários projetos de seu Centro de Pesquisa e Inovação Educacional. Cito dois, como exemplos ${ }^{6}$ : i) Inspirados pela tecnologia, norteados pela pedagogia: uma abordagem sistêmica das inovações educacionais de base tecnológica (OCDE, 2010); e, ii) Trabalhando com o Brasil (OCDE, 2017).

Em busca recente (2017) ao site do Banco Mundial ${ }^{7}$ foi possível identificar o registro de 534 projetos desenvolvidos ou em desenvolvimento no Brasil desde 1949 envolvendo os vários setores de atividade. $\mathrm{Na}$ área da educação (incluindo desenvolvimento social), são 40 projetos, dos quais 9 encontram-se ativos. Envolvendo a área de currículo, são 17 projetos, dos quais 1 encontra-se em andamento. Em geral, são ações relacionadas à gestão da educação e/ou do currículo cujas finalidades gravitam em torno da busca por melhoria da qualidade do ensino e da aprendizagem, eficiência escolar, redução dos índices de evasão e repetência, formação de professores, infraestrutura, etc.

Sobre as influências dos organismos transnacionais e, particularmente, sobre o Processo de Bolonha, Morgado (2009) faz importante advertência, marcando que, no domínio curricular, a tendência tem sido a progressiva europeização do currículo. Aliás, um forte movimento verificou-se atualmente no Brasil com a proposição de uma Base Nacional Comum Curricular (BNCC) inspirada nos ideários de centralização curricular de base internacional. Morgado chama a atenção para a possibilidade de enfraquecimento das territorialidades curriculares nacionais em favor de um conhecimento escolar internacional regulado.

\section{Indicativos do alinhamento do sistema educacional brasileiro em termos de metas, recomendações e orientações curriculares aos movimentos de internacionalização}

$\mathrm{Na}$ presente seção, apresento e analiso, com base nos documentos oficiais da política curricular e textos correlatos, eventos e processos educacionais que sinalizam, em alguma medida, o alinhamento dos sistemas de ensino brasileiro às demandas e aos requerimentos da internacionalização. 0 objetivo é verificar a presença e a intensidade desse movimento por intermédio dos textos das diretrizes curriculares da Educação Básica, especialmente as formuladas a partir dos anos 2000, quando todas as etapas e modalidades foram contempladas.

A identificação das marcas é feita tomando-se, dos textos na íntegra, os fragmentos que contêm expressões elencadas nos descritores do quadro 1, cujos conteúdos possuem alguma interface com temas correlatos à internacionalização ou a demandas internacionais, além de outros excertos que visivelmente apontam para essa perspectiva. A tabela a seguir mostra o resultado do trabalho de identificação em termos quantitativos, os quais, juntamente com a planilha contendo os fragmentos dos textos ${ }^{8}$, servem de base para a análise.

\footnotetext{
6- Diana Lemes Ferreira, em sua tese intitulada A OCDE e a política de formação docente no Brasil (2011), relaciona as políticas globais da OCDE com as ações do Estado brasileiro na área da educação, especialmente na formulação e implantação de programas como o Índice de Desenvolvimento da Educação Básica (IDEB), o Plano de Desenvolvimento da Educação (PDE), o Plano de Metas Compromisso de Todos pela Educação, o Programa de Incentivo à Docência (PRODOCENCIA), a Nova CAPES e a Universidade Aberta do Brasil (UAB). No trabalho revelam-se notórias as influências desse organismo multilateral sobre os currículos da Educação Básica brasileira.

7- Disponível em: <http://projects.worldbank.org/?lang=en>. Acesso em: 15 ago. 2017.

8- A planilha com os fragmentos dos textos das diretrizes não foi incluída no artigo devido à sua extensão, todavia compõe o material de pesquisa.
} 
Tabela 1 - Indicações relacionadas à internacionalização presentes nos textos das Diretrizes Curriculares Nacionais para a Educação Básica brasileira e suas modalidades

\begin{tabular}{|c|c|c|c|c|c|c|c|c|}
\hline \multirow[b]{2}{*}{ Documentos oficiais } & \multicolumn{8}{|c|}{$\begin{array}{l}\text { Descritores e número de marcações } \\
\text { nos textos }\end{array}$} \\
\hline & 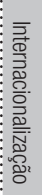 & 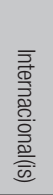 & 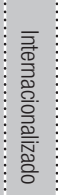 & 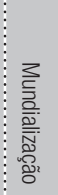 & 言 & 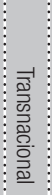 & 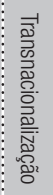 & $\begin{array}{l}\frac{\Omega}{\circ} \\
\stackrel{\circ}{\underline{O}}\end{array}$ \\
\hline $\begin{array}{l}\text { Parecer CNE/CEB nº 7, de 07/04/2010, e Resolução nº 04, de 13/07/2010: Fixam Diretrizes } \\
\text { Curriculares Nacionais Gerais para a Educação Básica. }\end{array}$ & 3 & 2 & 0 & 0 & 1 & 4 & 0 & 1 \\
\hline $\begin{array}{l}\text { Parecer CNE/CEB ñ 11/2010 e Resolução nº 7, de 14/12/2010: Fixam Diretrizes Curriculares } \\
\text { Nacionais para o Ensino Fundamental de } 9 \text { (nove) anos. }\end{array}$ & 0 & 2 & 0 & 0 & 0 & 0 & 0 & 2 \\
\hline $\begin{array}{l}\text { Parecer CNE/CEB nº 5/2011 e Resolução nº 2, de 30/01/2012: Fixam Diretrizes Curriculares } \\
\text { Nacionais para o Ensino Médio. }\end{array}$ & 0 & 6 & 0 & 0 & 2 & 0 & 0 & 1 \\
\hline $\begin{array}{l}\text { Parecer CNE/CEB nº 14/2011 e Resolução no 3, de 16/05/2012: Fixam Diretrizes para } 0 \\
\text { Atendimento de Educação Escolar de Crianças, Adolescentes e Jovens em Situação de Itinerância. }\end{array}$ & 0 & 0 & 0 & 0 & 0 & 0 & 0 & 0 \\
\hline $\begin{array}{l}\text { Parecer CNE/CEB nº 11/2012 e Resolução nº 6, de 20/09/2012: Fixam Diretrizes Curriculares } \\
\text { Nacionais para a Educação Profissional Técnica de Nível Médio. }\end{array}$ & 1 & 4 & 0 & 0 & 1 & 0 & 0 & 4 \\
\hline $\begin{array}{l}\text { Parecer n 36, de 04/12/2001, e Resolução CNE/CEB nº 1, de 03/04/2002: Fixam Diretrizes } \\
\text { Operacionais para a Educação Básica nas Escolas do Campo. }\end{array}$ & 0 & 0 & 0 & 0 & 0 & 0 & 0 & 2 \\
\hline $\begin{array}{l}\text { Parecer nº 20/2009 e Resolução nº 5, de 17/12/2009: Fixam Diretrizes Curriculares Nacionais } \\
\text { para a Educação Infantil }\end{array}$ & 0 & 0 & 0 & 0 & 0 & 0 & 0 & 0 \\
\hline $\begin{array}{l}\text { Parecer CNE/CEB nº 4/2010 e Resolução nº 2, de 19/05/2010: Fixam Diretrizes Nacionais } \\
\text { para a Oferta de Educação para Jovens e Adultos em Situação de Privação de Liberdade nos } \\
\text { Estabelecimentos Penais. }\end{array}$ & 0 & 17 & 0 & 0 & 0 & 0 & 0 & 1 \\
\hline $\begin{array}{l}\text { Parecer CNE/CEB ño 13/2012 e Resolução nº 5, de 22/06/2012: Fixam Diretrizes Curriculares } \\
\text { Nacionais para a Educação Escolar Indígena. }\end{array}$ & 0 & 11 & 0 & 0 & 0 & 0 & 0 & 0 \\
\hline $\begin{array}{l}\text { Parecer CNE/CEB nº 16, de 05/06/2012, e Resolução nº 8, de 20/11/2012: Fixam Diretrizes } \\
\text { Curriculares Nacionais para a Educação Escolar Quilombola. }\end{array}$ & 0 & 16 & 0 & 0 & 0 & 0 & 0 & 1 \\
\hline $\begin{array}{l}\text { Parecer CNE/CP ñ 003/2004 e Resolução n 1, de 17/06/2004: Fixam Diretrizes Curriculares } \\
\text { Nacionais para a Educação das Relações Étnico-Raciais e para o Ensino de História e Cultura } \\
\text { Afro-Brasileira e Africana. }\end{array}$ & 0 & 3 & 0 & 0 & 3 & 0 & 0 & 1 \\
\hline $\begin{array}{l}\text { Parecer CNE/CEB ño 13/2009 e Resolução nº 4, de 2/10/2009: Fixam Diretrizes Operacionais para } \\
\text { o Atendimento Educacional Especializado na Educação Básica, Modalidade Educação Especial. }\end{array}$ & 0 & 0 & 0 & 0 & 0 & 0 & 0 & 0 \\
\hline $\begin{array}{l}\text { Parecer CNE/CP nº 8/2012 e Resolução nº 1, de 30/05/2012: Fixam Diretrizes Nacionais para a } \\
\text { Educação em Direitos Humanos. }\end{array}$ & 0 & 15 & 0 & 0 & 5 & 0 & 0 & 3 \\
\hline $\begin{array}{l}\text { Parecer CNE/CP nº 14/2012 e Resolução nº 2, de 15/06/2012: Fixam Diretrizes Curriculares } \\
\text { Nacionais para a Educação Ambiental. }\end{array}$ & 0 & 9 & 0 & 0 & 5 & 0 & 0 & 3 \\
\hline $\begin{array}{l}\text { Parecer CNE/CP n 28, de 02/10/2001, e Resolução n 1, de 18/02/2002: Fixam Diretrizes } \\
\text { Curriculares Nacionais para a Formação de Professores da Educação Básica em Nivel Superior, } \\
\text { Curso de Licenciatura, de Graduação Plena. }\end{array}$ & 0 & 1 & 0 & 0 & 0 & 0 & 0 & 0 \\
\hline Base Nacional Comum Curricular, $3^{\mathrm{a}}$ versão, 2017 (em discussão no CNE). & 0 & 11 & 0 & 0 & 0 & 3 & 0 & 6 \\
\hline TOTAIS & 4 & 97 & 0 & 0 & 17 & 7 & 0 & 25 \\
\hline
\end{tabular}

Fonte: Elaborado pelo autor (em 2017), a partir de documentos oficiais (BRASIL, 2013; BRASIL, 2016; BRASIL, 2017a). 
Embora a busca tenha sido feita exclusivamente nos textos oficiais da política curricular brasileira, levo em conta que os indicativos de aproximação e/ou aderência a esse projeto transnacional revelam-se em outras ações do Estado brasileiro, como ilustrativamente mostro na figura a seguir - ainda que não as examine neste texto em razão de suas limitações.

Figura 1 - Ações oficiais alinhadas, em alguma medida, às demandas da internacionalização da educação e do currículo

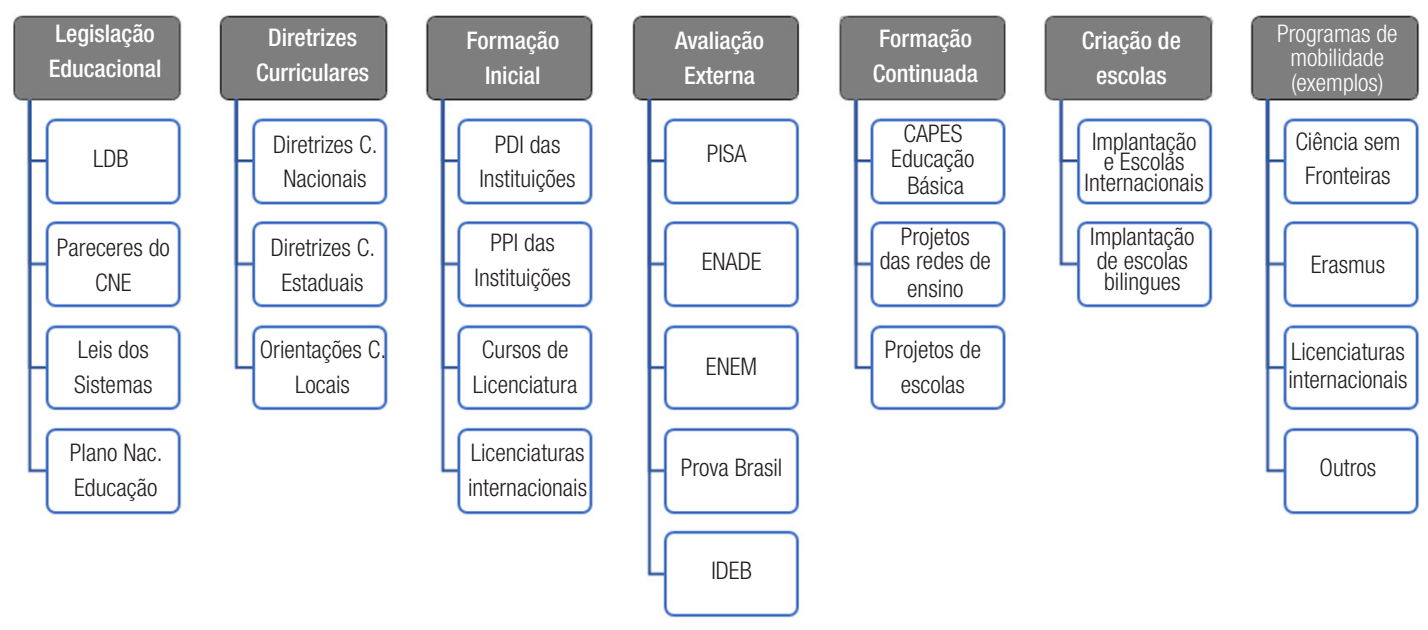

Fonte: Elaborado pelo autor (em 2017).

Particularmente no que se refere aos textos das Diretrizes Curriculares Nacionais para a Educação Básica brasileira e suas modalidades, constata-se a presença de várias marcações que, no âmbito discursivo, apontam haver relação entre a política curricular prescrita aos sistemas de ensino e os requerimentos e expectativas da internacionalização. 0 trabalho permite, inclusive, identificar alguns modos como o Brasil se move nesse processo e a intensidade de sua participação, conforme destacarei a seguir.

Em geral, as indicações aparecem relacionadas às questões da agenda estruturada para a educação em contextos de internacionalização traduzidas em discursos como: i) reconhecimento da existência de contextos, demandas e expectativas internacionais; ii) preocupação com efeitos e implicações das exigências internacionais; iii) expectativas em relação às demandas, especialmente no que se refere a resultados educacionais; iv) garantia de direitos em relação aos compromissos firmados em acordos, pactos e/ou convenções internacionais; v) inclusão de conteúdos curriculares que atendam aos requerimentos e padrões internacionais; vi) busca por acesso e participação nas redes e projetos sociais que circulam em escala internacional ou transnacional.

Assim, sobre essa base, pode-se afirmar que, no âmbito da Educação Básica, o Brasil dá os primeiros passos na direção de um alinhamento às demandas e aos requerimentos da internacionalização do currículo - um movimento que avalio ser caracterizado como do tipo passivo (LIMA; MARANHÃO, 2009), tendo em vista tratar-se de processos de ajuste ou conformação curricular aos padrões estabelecidos nos espaços centrais. Essa 
tipologia fica ainda mais evidenciada quando se verificam, nos textos, fortes preocupações dos formuladores com efeitos e implicações das exigências internacionais sobre nosso sistema de ensino. Note-se que não são preocupações que se convertem em formulação de estratégias de defesa ou crítica, mas sim em recomendações para seu pronto acolhimento.

As estratégias discursivas utilizadas na formulação dos textos da política curricular para este ajustamento são evidentes, especialmente porque afirmam ou reforçam, em praticamente todas as diretrizes, pressupostos, concepções e ideários dessa agenda transnacional. Nos pareceres que dão origem e, portanto, sustentam as resoluções que fixam as diretrizes, verificam-se marcados reconhecimento e acolhimento às expectativas e demandas internacionais em relação à educação. É comum encontrar nos textos, por exemplo, a preocupação em inserir a educação brasileira nos contextos da educação internacional - um horizonte que, aliás, assume sentido de finalidade.

Outro aspecto fortemente presente nos textos da política tem a ver com as expectativas internacionais no que se refere a resultados de aprendizagem. Não é raro encontrar marcações que acentuam as fragilidades do sistema de ensino brasileiro e a consequente necessidade de atenção aos índices de qualidade medidos por avaliação externa, a exemplo do IDEB e sua evidente relação com o PISA - relação acentuada pelo próprio Instituto Nacional de Estudos e Pesquisa Educacionais, órgão subordinado ao Ministério da Educação do Brasil que assim se manifesta:

0 Índice de Desenvolvimento da Educação Básica (IDEB) é o indicador objetivo para a verificação do cumprimento de metas fixadas no Termo de Adesão ao Compromisso "Todos pela Educação", eixo do Plano de Desenvolvimento da Educação fomentado pelo Ministério da Educação. Nesse âmbito se enquadra a ideia das metas intermediárias para o Ideb. 0 objetivo é alcançar a média de 6,0 em 2022 - período estipulado tendo como base a simbologia do bicentenário da Independência. Para isso, cada sistema deve evoluir segundo pontos de partida distintos e com esforço maior daqueles que partem em pior situação, visando reduzir a desigualdade educacional. A definição de uma meta nacional para o Ideb em 6,0 significa dizer que, considerando os anos iniciais do ensino fundamental, o país deve atingir em 2021 o nivel de qualidade educacional médio dos países membros da OCDE observado atualmente, em termos de proficiência e rendimento (taxa de aprovação). Essa comparação internacional foi possível devido à compatibilização entre a distribuição das proficiências observadas no Pisa e no Saeb. (BRASIL, 2016, grifos nossos).

$\mathrm{Na}$ mesma perspectiva, aparecem nos textos preocupações e consequentes recomendações dos formuladores para que os sistemas de ensino incluam nos currículos conteúdos de conhecimento que atendam aos requerimentos e padrões exigidos pelas avaliações externas. 0 exemplo mais evidente refere-se à formulação do texto da Base Nacional Comum Curricular (BNCC), recentemente aprovado no Conselho Nacional de Educação, que notadamente assume os conteúdos curriculares como "a serviço do desenvolvimento de competências” (BRASIL, 2017a, p. 15). Na introdução do documento, afırma-se:

No Brasil, essas referências legais (matrizes e competências) têm orientado a maioria dos Estados e Municípios na construção de seus currículos. Essa mesma tendência de elaboração de currículos 
referenciados em competências é verificada em grande parte das reformas curriculares que vêm ocorrendo em diferentes países desde as décadas finais do século XX e ao longo deste início do século XXI. É esse também o enfoque adotado nas avaliações internacionais da Organização para a Cooperação e Desenvolvimento Econômico (OCDE), que coordena o Programa Internacional de Avaliação de Alunos (Pisa, na sigla em inglês) e da Organização das Nações Unidas para a Educação, a Ciência e a Cultura (Unesco, na sigla em inglês), que instituiu o Laboratório Latinoamericano de Avaliação da Qualidade da Educação para a América Latina (LLECE, na sigla em espanhol). (BRASIL, 2017a, p. 16).

A busca por garantia de direitos em relação aos compromissos firmados em acordos, pactos e/ou convenções internacionais é, como assinalei, outra marca nos textos analisados. Essa preocupação mostra-se presente especialmente nas diretrizes para educação em direitos humanos, educação ambiental e de jovens e adultos em situação de privação de liberdade nos estabelecimentos penais, além de outras com menor intensidade. Neste âmbito, destaca-se com evidência a necessidade de atenção aos compromissos assumidos pelo Brasil em espaços globais. Na diretriz de educação ambiental, por exemplo, encontra-se que "no Brasil, a afirmação da Educação Ambiental nas diversas áreas situa-se no bojo da produção e participação nacional decorrente de acordos multilaterais e de legislações nacionais e internacionais" (BRASIL, 2013, p. 530).

Outro aspecto visivelmente marcado nos textos é a busca por acesso e participação do sistema de ensino brasileiro nas redes e nos projetos sociais que circulam em escala internacional. Na diretriz para a educação de jovens e adultos em situação de privação de liberdade, por exemplo, destaca-se a efetiva participação do Brasil nos projetos EUROSOCIAL ${ }^{9}$ e Red Latinoamericana de Educacion en Contextos de Encierro (Redlece) ${ }^{10}$.

No que se refere à dimensão da multiculturalidade, colocada como uma das expectativas para os processos de internacionalização da educação por alguns autores como Lima e Maranhão (2011), Moreira (2002), Knight (2012), Leask (2015), Lima e Contel (2011), não se verificaram marcações nos textos das diretrizes. As abordagens sobre cultura manifestadas nos documentos oficiais atribuem, em geral, destaque à diversidade que caracteriza a população brasileira e a consequente necessidade de atenção às diferenças étnico-raciais, de gênero e de orientação sexual. Não se observam formulações que indiquem a necessidade de trocas culturais em escala regional ou transnacional, exceto

\footnotetext{
9- EUROSOCIAL é um programa de cooperação técnica da União Europeia que objetiva contribuir na promoção da coesão social na América Latina pelo fortalecimento de políticas públicas e da capacidade institucional para executá-las. Seu método principal de trabalho é 0 intercâmbio de experiências, conhecimentos e boas práticas entre administrações públicas europeias e latino-americanas em cinco setores prioritários: justiça, educação, saúde, fiscalidade e emprego. Esse programa parte do convencimento de que é possível contribuir para melhorar a eficácia e a eficiência das políticas públicas com mecanismos geradores de coesão social através da sensibilização dos líderes políticos e dos intercâmbios de experiência entre funcionários públicos europeus e latino-americanos com capacidade de tomar decisões. A finalidade principal dos intercâmbios de experiência é a introdução de orientações, métodos ou procedimentos inovadores de gestão que têm sido utilizados em outros países (BRASIL, 2013).

10- A implementação da Rede, entre outros objetivos, tem como proposta: impulsionar políticas públicas integrais e integradas que favoreçam a atenção para a educação em espaços de privação de liberdade, concebida como um direito ao longo da vida; trocar experiências e informações, fomentando pesquisas e cooperação técnica entre os países; bem como atuar como um interlocutor regional para o diálogo e a reflexão política com outras redes em nível internacional (BRASIL, 2013).
} 
orientações para priorização da língua espanhola em razão do contexto linguístico que envolve o continente, além da participação do país no Mercosul.

No conjunto das diretrizes curriculares para as diferentes etapas e modalidades da Educação Básica, algumas delas não registram marcações evidenciando qualquer indicação ou vínculo com os contextos transnacionais ou com a expectativa de internacionalização do currículo. Ainda que estejam, todas, sob as mesmas normas do Sistema Nacional de Educação, dizem respeito a especificidades educacionais em processo de consolidação no quadro do sistema nacional, como é o caso da Educação Infantil, da Educação Especial e das diretrizes para o atendimento de educação escolar de crianças, adolescentes e jovens em situação de itinerância.

\section{Palavras finais}

0 trabalho que socializo no presente texto permitiu, entre outros aspectos, a (re)afırmação da hipótese que levantei para esta pesquisa, de que os movimentos de internacionalização do currículo, já evidentes na Educação Superior brasileira, alcançam também os territórios da Educação Básica, ainda que menos agressivamente. A análise dos textos da política curricular formulados a partir dos anos 2000 (período dos governos Luiz Inácio Lula da Silva e Dilma Roussef) revela não haver mudanças de perspectiva em relação ao que foi iniciado nos anos 1990 com o governo de Fernando Henrique Cardoso, que explicitamente reorientou o sistema educacional brasileiro para uma concepção neoliberal, tornando-o mais permeável aos interesses internacionais de toda a ordem.

Sobre esse aspecto, Ferreti e Silva (2017) destacam que o caldo de cultura que orientou a formulação das Diretrizes Curriculares Nacionais do Ensino Médio e, posteriormente, da Educação Profissional, na época de FHC foi constituído a partir do discurso do Governo Federal influenciado por entidades internacionais e por publicações como o Relatório Delors e a Cepal (Comissão Econômica para a América Latina). Ambos os documentos enfatizaram tanto a difusão do progresso técnico quanto a coesão social. Acrescento que nessa mesma direção caminhou a formulação dos chamados Parâmetros Curriculares Nacionais (PCN), processo que contemplou todas as etapas de modalidades da Educação Básica.

Com o governo de Michel Temer, verifica-se abertura ainda maior com efeitos concretos na Educação Básica. São exemplos: a Medida Provisória no 746/2016, agora convertida na Lei no 13.415/2017, que instituiu o chamado Novo ensino médio - prescrição claramente inspirada em modelos de países europeus e norte-americanos; além da proposição da terceira versão do texto da Base Nacional Comum Curricular, que notadamente atende aos requerimentos estrangeiros de centralização curricular e assume o currículo por competências como eixo central. Ambas as iniciativas tem visível alinhamento às demandas da internacionalização.

Enfım, concordo com Libâneo (2014), para quem a internacionalização é um fato concreto do mundo contemporâneo, expressão da dinâmica da realidade econômica, política e cultural. Para ele, os países emergentes ou pobres são induzidos a praticar políticas educacionais compatíveis com os interesses do mercado global e, para isso, os organismos multilaterais oferecem mecanismos de ajuda e financiamento. No sentido em 
que aponta Libâneo, poderíamos afırmar que os movimentos de internacionalização da educação e do currículo formam parte de um projeto globalmente estruturado movido predominantemente pelas forças dos organismos multilaterais.

\section{Referências}

AGUIAR, Andrea Moura de Souza. 0 recurso às escolas internacionais como estratégia educativa de famílias socialmente favorecidas. 2007. Tese (Doutorado em Educação) - Faculdade de Educação, Universidade Federal de Minas Gerais, Belo Horizonte, 2007.

AMORIM, Marina Alves. Educação dos brasileiros e o estrangeiro: breve histórico da internacionalização dos estudos no Brasil. Brasiliana Journal for Brazilian Studies, London, v. 1, n. 1, p. 44-65, set. 2012.

BALL, Stephen J. Educação Global S. A.: novas redes de políticas e o imaginário neoliberal. Tradução de Janete Bridon. Ponta Grossa: UEPG, 2014.

BALL, Stephen J. Educational reform: a critical and post-structural approach. Buckingham: Open University Press, 1994.

BALL, Stephen J.; MAINARDES, Jefferson (Org.). Políticas educacionais: questões e dilemas. São Paulo: Cortez, 2011.

BANCO MUNDIAL. Estratégia 2020 para a educação do grupo Banco Mundial: resumo executivo. Aprendizagem para todos: investir nos conhecimentos e competências das pessoas para promover 0 desenvolvimento. Washington, DC: Banco Mundial, 2011.

BANCO MUNDIAL. Prioridades y estrategias para la educación: examen del Banco Mundial. Washington, DC: Banco Mundial, 1996.

BRASIL. Instituto Nacional de Estudos e Pesquisas Educacionais Anísio Teixeira. 0 Pisa e o IDEB. Brasília, DF: Inep, 2016. Disponível em: <http://portal.inep.gov.br/pisa-e-0-ideb>. Acesso em: 08 ago. 2017.

BRASIL. Ministério da Educação. Base Nacional Comum Curricular: educação é a Base. Brasília, DF, MEC, 2017a. Disponível em: <http://cnebncc.mec.gov.br/docs/BNCC_Educacao_Infantil_e_Ensino_ Fundamental.pdf>. Acesso em: 15 ago. 2017.

BRASIL. Ministério da Educação. Secretária de Educação Básica. Diretrizes Curriculares Nacionais para a Educação Básica. Brasília, DF: MEC/SEB, 2013. Disponível em: <http://portal.mec.gov.br/docman/julho2013-pdf/13677-diretrizes-educacao-basica-2013-pdf/file>. Acesso em: 15 ago. 2017.

BRASIL. Presidência da República. Casa Civil. Lei no 13.415, de 16 de fevereiro de 2017b. Diário Oficial da União, Brasília, DF, 17 fev. 2017b. Disponível em: <http://www.planalto.gov.br/ccivil_03/_ato20152018/2017/lei/l13415.htm>. Acesso em: 20 nov. 2017. 
CÓSSIO, Maria de Fátima. Agenda transnacional e governança nacional: as possíveis implicações na formação e no trabalho docente. Revista e-Curriculum, São Paulo, v. 13, n. 4, p. 616-640, out./dez. 2015.

DALE, Roger. A globalização e o desenho do terreno curricular. Revista Espaço do Currículo, João Pessoa, v. 1, n. 1, p. 12-33, mar./set. 2008.

DALE, Roger. A sociologia da educação e o estado após a globalização. Educação \& Sociedade, Campinas, v. 31, n. 113, p. 1099-1120, out./dez. 2010.

DALE, Roger. Globalização e educação: demonstrando a existência de uma "cultura educacional mundial comum" ou localizando uma "agenda globalmente estruturada para a educação?". Educação e Sociedade, Campinas, v. 25, n. 87, p. 423-460, maio/ago. 2004.

EVANGELISTA, Olinda (Org.). 0 que revelam os "slogans" na política educacional. Araraquara: Junqueira \& Marin, 2014.

EVANGELISTA, Olinda. Qualidade da educação pública: estado e organismos multilaterais. In: LIBÂNEO, José Carlos; SUANNO, Marilza Vanessa Rosa; LIMONTA, Sandra Valéria (Org.). Qualidade da escola pública: políticas educacionais, didática e formação de professores. Goiânia: Ceped, 2013. p. 131-148.

EVANGELISTA, Olinda; SHIROMA Eneida 0. Educação para o alívio da pobreza: novo tópico da agenda global. Revista de Educação PUC, Campinas, v. 20, p. 43-54, 2006.

FERREIRA, Diana Lemes. A Organização para Cooperação e Desenvolvimento Econômico (OCDE) e a política de formação docente no Brasil. 2011. Tese (Doutorado em Educação) - Instituto de Ciências da Educação, Universidade Federal do Pará, Belém, 2011.

FERRETI, Celso João; SILVA, Mônica Ribeiro. Reforma do ensino médio no contexto da medida provisória no 746/2016: estado, currículo e disputas por hegemonia. Educação \& Sociedade, Campinas, v. 38, n. 139, p. 385-404, abr./jun. 2017.

FREITAS, Luiz Carlos de. Os reformadores empresariais da educação: a consolidação do neotecnicismo no Brasil. In: FONTOURA, Helena Amaral (Org.). Políticas públicas e movimentos sociais. Rio de Janeiro: Anped Sudeste, 2011. p. 72-90. Disponível em: <http://www.fe.ufrj.br/anpedinha2011/sobre.html>. Acesso em: 10 ago. 2017.

FREITAS, Luiz Carlos de. Os reformadores empresariais da educação: da desmoralização do magistério à destruição do sistema público de educação. Educação \& Sociedade, Campinas, v. 33, n. 119, p. 325-672, abr./jun. 2012.

FRIGOTTO, Gaudêncio; CIAVATTA, Maria. Educação básica no Brasil na década de 1990: subordinação ativa e consentida à lógica de mercado. Educação \& Sociedade, Campinas, v. 24, n. 82, p. 93-130, 2003.

KNIGHT, Jane. Internationalization remodeled: definition, approaches and rationales. Journal of Studies in International Education, Washington, DC, v. 8, n. 1, p. 5-31, 2004.

KNIGHT, Jane. Higher education in turmoil: the changing world of internationalization. Rotterdam: Sense, 2008. 
KNIGHT, Jane. Student mobility and internationalization: trends and tribulations. Research in Comparative \& International Education, Oxford, v. 7. n. 1, p. 20-23, 2012.

LEASK, Betty. Internationalizing the curriculum. New York: Routledge, 2015.

LEASK, Betty. Using formal and informal curricula to improve interactions between home and international students. Journal of Studies in International Education, v. 13, n. 2, p. 205-221, 2009.

LEHER, Roberto. Da ideologia do desenvolvimento à ideologia da globalização: a educação como estratégia do Banco Mundial para o alívio da pobreza. 1998. Tese (Doutorado em Educação) - Faculdade de Educação, Universidade de São Paulo, 1998.

LIBÂNE0, José Carlos. Internacionalização das políticas educacionais: elementos para uma análise pedagógica de orientações curriculares para o ensino fundamental e de propostas para a escola pública. In: SILVA, Maria Abádia; CUNHA, Célio da (Org.). Educação básica: políticas, avanços, pendências. Campinas: Autores Associados, 2014. p. 13-56.

LIMA, Manolita Correia; CONTEL, Fábio Betioli. Internacionalização da educação superior: nações ativas, nações passivas e a geopolítica do conhecimento. São Paulo: Alameda, 2011.

LIMA Manolita Correia; MARANHÃO, Carolina Machado Saraiva de Albuquerque. 0 sistema de educação superior mundial: entre a internacionalização ativa e passiva. Avaliação, Campinas, v. 14, n. 3, p. 583-610, nov. 2009.

LIMA Manolita Correia; MARANHÃO, Carolina Machado Saraiva de Albuquerque. Políticas curriculares da internacionalização do ensino superior: multiculturalismo ou semiformação? Ensaio, Rio de Janeiro, v. 19, n. 72, p. 575-598, jul./set. 2011.

MOREIRA, Antonio Flávio Barbosa Currículo, diferença cultural e diálogo. Educação \& Sociedade, Campinas, v. 23, n. 79, p. 15-38, ago. 2002.

MORGAD0, José Carlos. 0 processo de Bolonha e ensino superior num mundo globalizado. Educação \& Sociedade, Campinas, v. 30, n. 106, p. 37-62, jan./abr. 2009.

NOGUEIRA, Maria Alice; AGUIAR, Andrea Moura de Souza; RAMOS, Viviane Coelho Caldeira. Fronteiras desafiadas: a internacionalização das experiências escolares. Educação \& Sociedade, Campinas, v. 29, n. 103, p. 355-376, maio/ago. 2008.

OCDE. Inspirados pela tecnologia, norteados pela pedagogia, uma abordagem sistêmica das inovações educacionais de base tecnológica. [S. I.]: Centro de Pesquisas Educacionais e Inovação, 2010. Disponível em: <http://www.oecd.org/education/ceri/47785311.pdf>. Acesso em: 18 out. 2017.

OECD. OECD yearbook 2011: better policies for better lives. [S. I.]: OECD, 2011. Disponível em: <https:// www.oecd-ilibrary.org/docserver/observer-v2010-6-en.pdf?expires=1550172287\&id=id\&accname=gue st\&checksum=92857B2DDF753E339B10FFB46167F8CF>. Acesso em: 20 out. 2017.

OCDE. Trabalhando com o Brasil. [S. I.]: OECD, 2017. Disponível em: <http://www.oecd.org/latin-america/ Active-with-Brazil-Port.pdf>. Acesso em: 10 dez. 2017. 
PACHECO, José Augusto; MARQUES, Micaela. Governabilidade curricular: ação dos professores em contextos de avaliação externa. In: OLIVEIRA, Maria Rita (Org.). Professor: formação, saberes, problemas. Porto: Porto Editora, 2014. p. 105-135.

SEVILHA, Gustavo Brechese. A internacionalização do ensino básico, suas motivações. 2014. Dissertação (Mestrado) - Universidade de São Paulo, São Paulo, 2014.

SILVA, Maria Abádia. Organismos internacionais e a educação. In: OLIVEIRA, Dalila; DUARTE, Adriana Cancella; VIEIRA, Livia Fraga (Org.). Dicionário: trabalho, profissão e condição docente. Belo Horizonte: UFMG, 2010. CD-ROM.

SUDBRACK, Edite Maria; NEGRO Arnaldo. Internacionalização e educação: impactos nas políticas educacionais. RP3: Revista de Pesquisa em Políticas Públicas, Brasília, DF, n. 7, p. 44-57, 2016.

THIESEN, Juares da Silva. Internacionalização dos currículos na educação básica: concepções e contextos. Revista e-Curriculum, São Paulo, v. 15, n. 4, p. 991-1017, out./dez. 2017.

UNESCO. A Declaração de Nova Delhi sobre Educação Para Todos. Nova Delhi: Unesco, 1993. Disponível em: <http://unesdoc.unesco.org/images/0013/001393/139393por.pdf>. Acesso em: 10 ago. 2017.

UNESCO. 0 marco de Ação de Dakar Educação Para Todos: atendendo nossos compromissos coletivos. Dakar: Cúpula Mundial de Educação, 2000.

UNICEF. Brasil. Declaração Mundial sobre Educação para Todos: Conferência de Jomtien. Jomtien: Unicef, 1990. Disponível em: <https://www.unicef.org/brazil/declaracao-mundial-sobre-educacao-para-todosconferencia-de-jomtien-1990>. Acesso em: 10 ago. 2017.

WIELEWICK, Hamilton de Godoy; OLIVEIRA, Marlize Rubin. Internacionalização da educação superior: Processo de Bolonha. Ensaio, Rio de Janeiro, v. 18, n. 67, p. 215-234, abr./jun. 2010.

Recebido em: 11.01.2018 Modificações em: 04.04.2018

Aprovado em: 25.04.2018

Juares da Silva Thiesen é doutor em Educação e em Gestão do conhecimento, com pós-doutoramento em Desenvolvimento Curricular pela Universidade do Minho (Braga, Portugal). Atualmente é professor do Centro de Ciências da Educação e do Programa de Pós-Graduação em Educação (PPGE) da Universidade Federal de Santa Catarina (UFSC), atuando como líder do Grupo de Pesquisa em Estudos Curriculares (ITINERA). 